\title{
Frameshift Mutation
}

National Human Genome Research Institute (NHGRI)

\section{Source}

National Human Genome Research Institute (NHGRI). Frameshift Mutation.

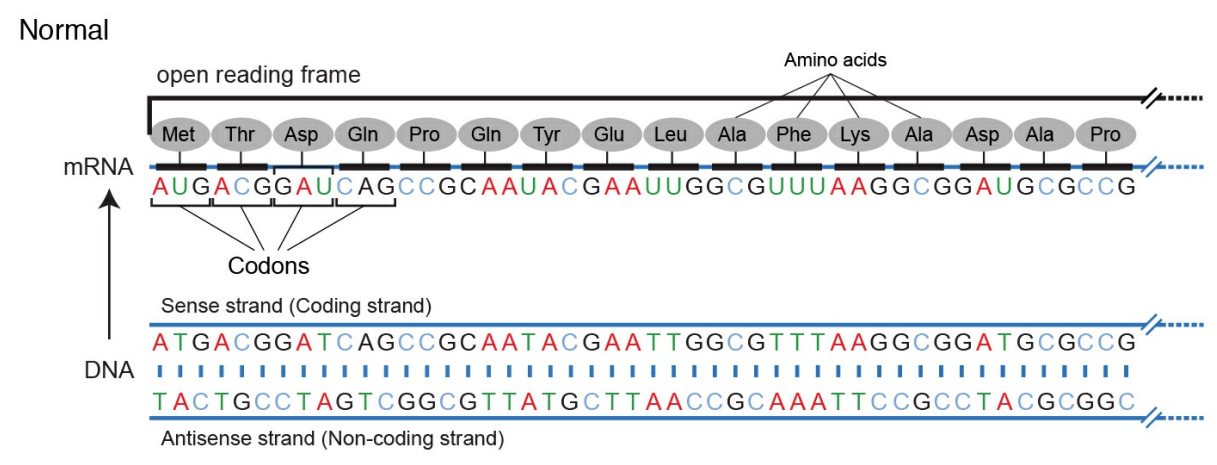

Frameshift mutation - single nucleotide insertion

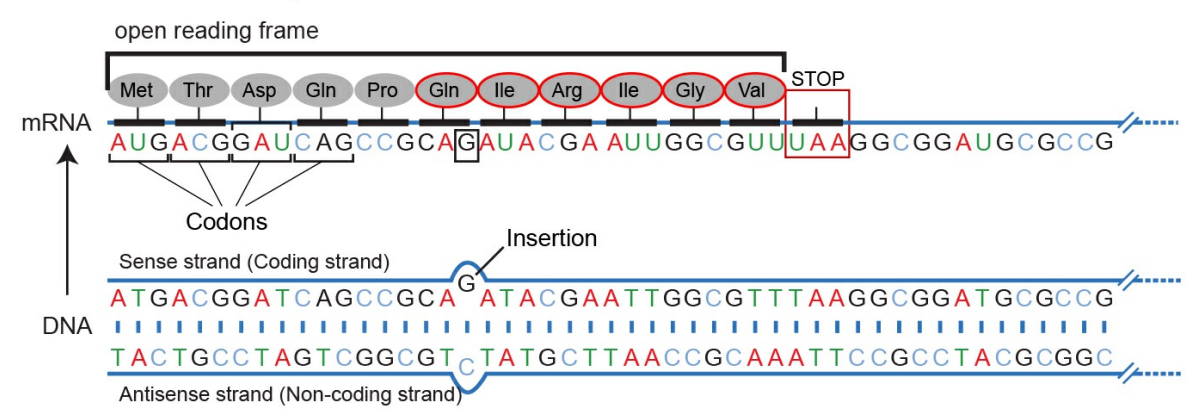

A frameshift mutation is a type of mutation involving the insertion or deletion of a nucleotide in which the number of deleted base pairs is not divisible by three. "Divisible by three" is important because the cell reads a gene in groups of three bases. Each group of three bases corresponds to one of 20 different amino acids used to build a protein. If a mutation disrupts this reading frame, then the entire DNA sequence following the mutation will be read incorrectly. 